\title{
Willingness to pay and QALYs: What can we learn about valuing foodborne risk?
}

\author{
Henrik Andersson, James K. Hammitt, and Kristian Sundström*
}

March 10, 2015

\begin{abstract}
We examine the value of reducing foodborne risk. Previous research on the valuation of health risk has been dominated by the study of mortality risk. However, in most cases foodborne illnesses are non-fatal so we focus on individuals' preferences for reducing morbidity risk, while also including a realistic, if remote, chance of death. We use a contingent valuation method on a Swedish sample and we estimate a value of a statistical illness (VSI) consistent with previous findings in the literature. We also examine how willingness to pay (WTP) varies with the expected change in quality-adjusted life years (QALYs) and estimate the WTP per QALY. We find that WTP increases with, though less than proportionally to a change in QALYs. However, our results also suggest that respondents may have found it difficult to evaluate compound risks of both morbidity and mortality simultaneously.
\end{abstract}

Keywords Contingent valuation, Food risks, QALY, Willingness to pay

JEL codes D80; I10; Q18

Published as: Andersson, H., Hammitt, J.K., Sundström, K., 'Willingness to pay and QALYs: What can we learn about valuing foodborne risk?', Journal of Agricultural Economics, vol. 66, n. 3, September 2015, pp. 727-752.

*Henrik Andersson, Toulouse School of Economics (LERNA, UT1C, CNRS), France (to whom correspondence should be addressed, henrik.andersson@tse-fr.eu), James K. Hammitt, Center for Risk Analysis, Harvard University, USA, and Toulouse School of Economics (LERNA, INRA), France, and Kristian Sundström, Institute for Food and Agricultural Economics, Lund University, Sweden. Henrik Andersson acknowledges financial support from VTI and the Centre for Transport Studies, Stockholm. The authors are grateful to the reviewers for their helpful comments on earlier drafts. The usual disclaimers apply. 


\section{Introduction}

Foodborne illness is an important global health threat and many countries devote substantial resources to preventing the emergence and spread of zoonotic and other foodborne diseases. For example, to prevent the spread of salmonella, Swedish public authorities spend between US\$ 8 to 14 million each year (SJV, 2007), in addition to more or less compulsory investments at the producer level. These expenses can only be justified if they can be shown to provide greater benefits to society in relation to their costs than alternative measures.

Health related benefits are generally harder to value than costs, however, and policy makers have therefore largely relied on cost-effectiveness analysis (CEA) to guide health policies. Thus, policies have been evaluated based on information about their technical efficiency. Health effects are often quantified using quality-adjusted life years (QALYs) (Pliskin et al., 1980; Hammitt, 2002) and interventions are evaluated by the cost per expected QALY gained. The use of CEA with QALYs separates the decision problem into: (i) comparing the cost-effectiveness (CE) of interventions and (ii) deciding on acceptability thresholds for CE ratios. The former evaluates the efficiency of the intervention and the latter whether it should be implemented. Hence, it is not necessary to assign monetary values to the interventions' different health outcomes when employing CE as the decision rule. However, without putting a monetary value on the benefits, it is difficult to compare policies between health and other domains.

There has been a growing interest in examining and estimating monetary values for QALYs (e.g., Gyrd-Hansen, 2003; Pinto-Prades et al., 2009; Mason et al., 2009; Haninger and Hammitt, 2011). Costeffectiveness analysis evaluating interventions per expected QALY gained is consistent with benefit-cost analysis (BCA) if and only if QALYs are valid measures of utility and willingness to pay (WTP) per QALY gained is constant in the population (Johannesson, 1995; Hammitt, 2002). Hence, when consistent, BCA and CEA will simply provide alternative approaches to presenting the same information. However, whereas the WTP approach is relatively easy to adopt for mortality risk reductions, since there is little variation in the endpoint ${ }^{1}$, direct estimation of individuals' WTP to reduce morbidity risks for each possible health state is infeasible due to the large variation among endpoints. This has motivated research on WTP per QALY where two main approaches have been taken; direct estimation and estimation based on estimates of the value of a statistical life (VSL).

Direct estimation elicits individuals' WTP for specified interventions where both the duration and the severity may be allowed to vary (Gyrd-Hansen, 2003; Pinto-Prades et al., 2009; Haninger and Hammitt, 2011). The alternative approach has been to derive a monetary value per QALY gained from available

\footnotetext{
${ }^{1}$ WTP to reduce mortality risk may be sensitive to the cause of death. See Viscusi (2010).
} 
estimates of VSL (French and Mauskopf, 1992; Mason et al., 2009; Tolley et al., 1994). VSL estimates are widely available and are used by policy makers in many countries (Viscusi and Aldy, 2003; Andersson and Treich, 2011). QALYs are estimated by combining information about "health-related quality of life" (HRQL) in specific health states with the amount of time spent in that state. Since HRQL is available for many health states it is relatively easy to estimate the change in QALYs for a morbidity endpoint and to multiply by WTP per QALY to obtain a monetary value. This approach assumes, however, that WTP per QALY is constant, which is why it is important to empirically examine whether this is indeed the case.

In this study we focus on individual preferences for food safety. Two methods exist to obtain estimates of the monetary benefits of food safety programs: the revealed preference (RP) and the stated preference (SP) method. In the RP method consumer decisions in existing markets are used to estimate WTP. WTP is often represented as the value of a statistical case (VSC) and the VSL, referring to the marginal WTP for a non-fatal and fatal risk reduction, respectively. The RP method has primarily been applied to labor markets, where wages for jobs with differing mortality risks have been used to calculate implicit values of risk differences (Viscusi and Aldy, 2003). The SP method, on the other hand, relies on a hypothetical decision about the good or attribute in question. The main benefit of the SP method is that it is very flexible and can be used to value goods or attributes for which no market exists. Empirically, however, it has been shown that this hypothetical characterisation of the decision can produce biased responses: respondents may answer strategically rather than consistently in line with their preferences; design features such as values presented or information provided may influence answers because the scenario may be perceived to be unrealistic or inconsequential (Bateman et al., 2002; Cameron, 1988).

The aim of this study is to elicit individual preferences for reducing salmonella risk. We chose the SP approach for several reasons. Food safety has many features that make it a candidate for market failure: (i) information about the level of safety is asymmetric, with producers generally having more knowledge (and ability to collect information) than consumers, (ii) food safety is often described as either an experience attribute or a credence attribute, which means that consumers cannot determine the risk before consumption (if at all) (Antle, 1995), and (iii) even if all information were symmetric and complete, a utility-maximizing choice would require that consumers be able to appreciate all the safety information provided and to translate it into relevant probabilities of suffering any of several adverse health effects. Empirical studies have indicated, however, that humans apply only a bounded rationality in this regard, implying that only limited parts of the information provided will actually be processed (Simon, 1990). All these factors suggest that a market solution will not be able to provide the optimum level of food safety in a society, so that market prices will no longer appropriately reflect consumer and 
societal preferences (Golan et al., 2005). A further reason is the flexibility of the SP approach which enables us to design scenarios and extract specific information that we need for our analysis, such as the respondents' subjective health levels.

Both motivations for the use of the SP approach are important for the two main objectives of our paper, i.e. to examine: (i) risk comprehension and WTP, and (ii) the empirical relationship between WTP and QALYs. Using a Swedish sample we design a choice scenario familiar to respondents, i.e. to choose between foods with different levels of risk of illness. The risk scenario was designed to be highly realistic in terms of risk levels and outcomes. Given that the scenario is realistic and familiar respondents should be able to appreciate the risk information provided in the survey when making their decisions. A novel aspect of our analysis of WTP per QALY is that we use an ex ante risk scenario (Haninger and Hammitt, 2011) instead of the more usual ex post scenario (e.g., Gyrd-Hansen, 2003; Pinto-Prades et al., 2009). The difference is that in the ex ante scenario individuals are asked about a scenario with a risk of experiencing a bad health state and to provide their WTP to reduce the probability of the bad outcome, whereas in the ex post scenario there is no uncertainty about the states and individuals are asked to imagine themselves being in the impaired state and to provide their WTP to shift to the good state. There are important policy implications for health evaluation if values from ex ante and ex post scenarios differ. Values per statistical case of illness elicited from ex ante and ex post perspectives may differ for several reasons: (1) Since the value per statistical case is obtained by dividing WTP by the change in the probability of the bad outcome (see Eq. (3) below), the VSC derived from the ex ante approach will decrease with the size of the risk reduction. Although WTP should increase with the risk reduction, the increase will be less than proportionate (because it is influenced by the respondent's budget constraint). Ex post VSC values a large change in probability (from 1 to 0 ) and may be much smaller than ex ante WTP (which values a small change in probability, e.g., 1/1,000). (2) If respondents do not understand probabilities or evaluate lotteries using non-linear transforms of probability (as in prospect theory, for example), the value per statistical case will depend on the probability change. (3) Loss aversion suggests individuals may value the ex ante loss more than the ex post gain.

One objective of our paper is to estimate monetary values for reducing salmonella risk. We report a preferred estimate of the value of reducing morbidity risk, which we refer to as the value of a statistical illness (VSI); we do not report an estimate of VSL because our survey design does not provide sufficient resolution to estimate respondents' preferences for mortality risk.

The remainder of the paper is organized as follows. We start by providing a brief summary of the theoretical framework. Sections 3, 4, and 5 contain a description of the survey, empirical models used for estimation, and the results. In the final section, we discuss our findings. 


\section{The theoretical framework}

In this study, we are interested in two alternative approaches to valuing reductions in health risks, WTP and QALYs. In the following two sections we briefly describe these approaches. ${ }^{2}$

\subsection{Willingness to pay}

The WTP approach is usually defined for a scenario with uncertain health outcomes; the individual has a specified probability of being sick $(s)$ or healthy $(h)$. The value to an individual of a reduced health risk is estimated by the individual's WTP for a reduction in the risk of illness and the framing of the scenario is usually the state-dependent expected utility model (Rosen, 1988),

$$
E U(w, p)=p u_{s}(w)+(1-p) u_{h}(w)
$$

where $p$ denotes the baseline probability of being sick and $u_{l}(w), l \in\{s, h\}$, the state-dependent utility of wealth $(w)$. The monetary amount an individual is willing to forgo to reduce the risk level can be derived by totally differentiating Eq. (1) while holding expected utility constant, which provides the standard expression,

$$
\mathrm{VSC}=\left.\frac{d w}{d p}\right|_{E U \text { constant }}=\frac{u_{h}(w)-u_{s}(w)}{p u_{s}^{\prime}(w)+(1-p) u_{h}^{\prime}(w)},
$$

where the prime denotes the first derivative. This expression, referred to as the value of a statistical case (VSC), is the marginal rate of substitution (MRS) between health risk and wealth. When $u_{s}(w)$ denotes the state-dependent utility of wealth if dead, Eq. (2) defines the VSL. Standard assumptions are that: (i) the utility of wealth is non-negative and at least as large when healthy as when sick $\left(u_{h} \geq u_{s}\right)$, (ii) the marginal utility of wealth is non-negative and at least as high when healthy as when sick $\left(u_{h}^{\prime} \geq u_{s}^{\prime}\right.$, $u_{h}^{\prime}>0$, and $u_{s}^{\prime} \geq 0$ ), and (iii) individuals are weakly risk averse $\left(u_{l}^{\prime \prime} \leq 0\right)$ (Hammitt, 2013). These assumptions are sufficient for the VSC and VSL to be positive and increasing with wealth and baseline risk (Weinstein et al., 1980; Pratt and Zeckhauser, 1996). Moreover, WTP increases with severity of illness $^{3}$ and it can be shown that WTP should be nearly proportional to small changes in risk (Hammitt, 2000).

Equation (2) defines the marginal WTP. In many empirical applications the estimated WTP is nonmarginal, for instance when respondents in an SP study are asked to state their WTP. ${ }^{4}$ For a small (but

\footnotetext{
${ }^{2}$ See, e.g., Hammitt (2002) for a more comprehensive description.

${ }^{3}$ This follows if severity is defined by (or perfectly correlated with) the ranking of illnesses by their effects on utility; i.e., illness $s$ is more severe than illness $r$ iff $u_{s}(w)<u_{r}(w)$.

${ }^{4}$ The value to an individual of a reduced health risk is conventionally estimated by his/her WTP for a reduction in the risk of illness. Alternatively respondents could be asked about their willingness to accept (WTA) compensation to forgo the risk reduction. For small changes in risk we expect WTP and WTA to be close to equal in magnitude and nearly proportional to the change in the reduction in risk (Hammitt, 2000). Empirical evidence suggests, though, that elicited WTA > PTP (Horowitz and McConnell, 2002; Tunçel and Hammitt, 2014).
} 
finite) risk reduction, $\Delta p, \mathrm{VSC}$ is therefore estimated as the ratio between $\mathrm{WTP}$ and $\Delta p$,

$$
\mathrm{VSC}=\frac{\mathrm{WTP}}{\Delta p}
$$

In our empirical analysis $p$ denotes the risk of illness and we will therefore from now on refer to Eq. (3) for the morbidity case as the value of a statistical illness (VSI).

\subsection{QALYs}

The QALY framework provides a method to value health interventions. It does not estimate a monetary value, instead the number of QALYs for a specific time interval of $M$ periods is given by a quality weighted duration according to

$$
\text { QALYs }=\sum_{i=1}^{M} q_{i} T_{i},
$$

where $q_{i}$ and $T_{i}$ refer to the weight and the duration of period $i$. The weight $q_{i}$ represents the quality of health in period $i$ (the HRQL) and can be estimated with techniques such as standard gamble or time-tradeoff questions (Bleichrodt and Johannesson, 1997) or classification systems such as the health utilities index (Feeny et al., 2002) and the EQ-5D (EuroQol Group, 1990). It is usually scaled such that one corresponds to perfect (or excellent) health and zero to a health state equivalent to death. It is evident from Eq. (4) that QALYs increase with $q_{i}$ and $T_{i}$ and the value of a health intervention is given by the difference in QALYs between the health profiles, i.e. with and without intervention. If preferences are consistent with QALYs, it can be shown that marginal WTP for an increase in QALYs should be positive but decreasing (Hammitt, 2013).

Whereas few constraints are placed on WTP, for QALYs to be consistent with individuals' preferences for health several rather restrictive conditions must be satisfied, including mutual utility independence of health and longevity, constant proportional tradeoff of longevity and health, risk neutrality for longevity, and preferences for tradeoffs between health and longevity independent of income (Pliskin et al., 1980; Hammitt, 2002).

\section{Contingent valuation survey}

\subsection{Data collection and questionnaire design}

The survey was mailed to 1898 randomly selected Swedish citizens among all Swedish households. Prior to the main survey, the questionnaire was tested in focus groups and in a pilot. When receiving the questionnaire the respondents were were told the information that they will provide is important for how society allocate resources and they were informed that they had the opportunity to complete the 
questionnaire on the web or by returning the paper questionnaire by post. ${ }^{5}$ A total of 920 questionnaires were returned after two reminders. Taking into account that 34 surveys could not be delivered, because recipients had moved or the address was incorrect, our final response rate was 49.4 percent. ${ }^{6}$ Of the 920 returned questionnaires 46 had been completed on the web. The postal and the web version of the survey were identical but due to differences between the two formats, survey heterogeneity cannot be ruled out. Results were not sensitive to adding the web answers to the postal data and we therefore decided to pool the answers from both survey modes. All respondents were offered a lottery ticket [value SEK 25 (US\$ 3.40$)^{7}$ ] if the questionnaire was returned and registered successfully. This reward had the effect that 103 empty questionnaires were returned, but these are not included in the response rate reported above.

The questionnaire employed in the main survey comprised five subsections. ${ }^{8}$ The objectives of the first section were manifold. First a number of rather simple questions were provided with the main purpose of getting the respondents "warmed-up" and ready for the rest of the questionnaire. A second objective was to gain information about the accuracy of each respondent's risk perceptions. Questions with this purpose included estimating the percentage of Swedish citizens that become sick by eating contaminated food annually as well as a question where various causes of death (including food-related illness) were to be ranked according to their fatality rates. A final objective of the first section was to investigate the levels of knowledge and experience of the respondents concerning handling of raw chicken meat.

In the second part of the survey, a training session was provided. The respondents were given a scenario where they had to choose between two types of eggs that differed in their probabilities of causing salmonellosis as well as in the retail prices they commanded. The aim of this exercise was to make the respondents familiar with the hypothetical WTP scenario. After having chosen between the two egg brands, the respondents were given feedback, in which their choice was analyzed from a safetyvs-price perspective. ${ }^{9}$ A visual aid consisting of 10000 white squares, in which the different risks were

\footnotetext{
${ }^{5}$ Two concerns about using a mail survey are the risk of obtaining a low response rate and the potential selection bias if only individuals interested in the subject answer the survey. As we achieved a reasonably large response rate and our sample is representative of the general population (see section 5.1.1) we do not consider our choice of survey mode to have affected the reliability of our results. Potential selection bias is a concern for other survey modes, as well. However, a weakness of the mail survey is that the order in which respondents answer the survey and their ability to revise a previous answer cannot be controlled. We did not include any elements that must be addressed in a specified order.

${ }^{6}$ No follow-up survey was conducted among those who did not answer the questionnaire. We therefore have no information whether those who answered our survey differ from those who did not. See section 5.1.1 for the representativeness of our sample.

${ }^{7}$ SEK $1=$ US\$ 0.136 (http://www.riksbank.se, 2011-10-27)

${ }^{8}$ Questionnaire (freely translated from Swedish to English) is available at www.agrifood.se/Files/SLI_VTI_Survey.pdf.

${ }^{9}$ To mitigate the risk of the training session influencing the answers to the actual WTP question, the feedback provided was neutral and only explained the choice to the respondent. For instance, if the respondent chose the more expensive and
} 
visualized as black squares, was also provided to aid risk communication. ${ }^{10}$ Respondents were informed that the social security system would cover any financial losses and medical expenditures due to illness. Finally, they were also reminded about their budget constraint.

The third and fourth sections contained two WTP scenarios. The WTP scenario of interest to this study was presented in section three of the questionnaire and is described in detail in the following section. Section four of the questionnaire contained questions on respondents' preferences for car safety. The findings on WTP for car safety are analyzed in Andersson et al. (2013) and in this paper we report only the results on food safety. Finally, the fifth section contained follow-up questions on respondents' demographics and socio-economics.

\subsection{Risk scenario, perceived health, and willingness to pay}

The questions about salmonellosis risk were developed to be highly realistic. As an introduction to the main valuation questions, some basic facts about salmonellosis and how common it is were presented. The severity of a case of salmonellosis can vary widely. Hence, for realism, we informed respondents that if they became sick, their illness might be mild, moderate or severe. Respondents were informed about the probability of the different states, the severity of the symptoms, the number of days they were expected to last, and if those infected would need to consult a physician (GP) or even to be hospitalized. The different characteristics included in this discussion are summarized in Table 1 below.

[Table 1 about here.]

Respondents were then asked to quantify the severity of these different states of salmonellosis. For this purpose we used the visual analog scale (VAS). Respondents were presented with a numbered scale with values ranging from zero (labeled "as bad as being dead") to 100 ("perfect health"). They were asked to "write down the number on the scale that you believe best describes your health" conditional on having the specified symptoms during one day. Respondents were also asked to quantify their "current general health status" using the same scale.

As a next step the main valuation scenario was introduced. Two different brands of chicken filet were described - a normal risk variant and a low risk alternative. The low risk chicken filet was described as being produced using a specific food safety programme entitling it to bear a uniquely identifiable label. The choice situation was then presented to the respondents as follows (freely translated from Swedish):

safer egg brand, it was explained that this implied he "in this case felt that the difference in the risk of salmonella between the two egg brands was sufficient to motivate the price premium" (freely translated from Swedish). Neither alternative was dominant, and hence we cannot use the answers to this question to test for scenario comprehension.

${ }^{10}$ Corso et al. (2001) found that using such visual aids can greatly enhance the communication of risk levels, leading to near proportionality between WTP and the stated risk reduction, in accordance with theory. 
"Imagine that, in your grocery store, there are two different brands of chicken filet to choose from, one which meets the safety program requirements (chicken filet low risk) and one that does not comply with these requirements (chicken filet normal risk). Each package contains $1 \mathrm{~kg}$ of chicken filet. The risk of getting salmonellosis from $1 \mathrm{~kg}$ chicken filet normal risk is [4] in 10000 , which implies that, on average, [4] out of 10000 packages will make you ill from salmonellosis. If, instead, you choose to buy $1 \mathrm{~kg}$ chicken filet low risk, you reduce this probability to [2] in 10 000." (Numbers in brackets vary among respondents.)

For a subset of the respondents it was then described that there was also a positive mortality risk from consuming chicken filet with salmonellosis that could be reduced by buying the safer chicken filet. The different combinations of morbidity and mortality risks related to the two brands were randomly distributed among the sampled population (and also among the completed surveys). In Table 2, the first column indicates the baseline morbidity risk (i.e. risk of getting salmonellosis after consuming the normal risk variant of chicken filet), the final morbidity risk (corresponding risk for the low risk variant), and the morbidity risk reduction. The remaining columns show the corresponding marginal mortality risks. Three baseline mortality risks were used: 0 in 100 million, 6 in 100 million and 12 in 100 million. The mortality risk reduction is always proportional to the morbidity risk reduction. In all, 12 different goods (combinations of mortality and morbidity risk reductions) were used in the sample.

[Table 2 about here.]

Each respondent was asked to value only one of these combination of risks. In addition to being presented as text in a matrix, the initial and final morbidity risks were also visualized graphically in terms of a grid with 10000 white squares, similar to the one that was used in the training section as described above. After having been presented with the relevant combination of risks, each respondent was asked if he or she would be willing to pay a certain specified extra premium in order to get the low risk chicken filet rather than the normal risk variant. Respondents were asked to assume that only they would consume the chicken they bought and they were reminded of their budget constraint. Respondents were randomly assigned one of five initial premium (or bid) levels: SEK 2, 10, 20, 40 or 60. Depending on the response to this question, the bid was then lowered (in case the respondent answered no to the initial bid) or increased (if the first answer was positive), and the respondent was then asked if he or she would be willing to pay this new bid (or premium) in order to get the low risk chicken. This elicitation method, the double-bounded (DB) dichotomous choice method (Hanemann et al., 1991), thus implies that each respondent had to select one out of four different answering schemes: yes-yes (yes to initial bid and yes to increased bid), yes-no, no-yes and no-no. Using the respondents' answer only to the initial 
bid is equivalent to asking only the initial question and is referred to as the single-bounded (SB) format. Because of concern that responses to the follow-up question can be influenced by the bid presented in the initial question (Bateman et al., 2002; Watson and Ryan, 2007), we estimate WTP using both DB and SB formats.

In case of a yes-yes reply, the questionnaire also included an open-ended follow-up question asking about the maximum premium that would still induce the respondent to buy the low risk variant of the chicken. Similarly, in case of a no-no answer, the respondent was asked to state the minimum premium at which he or she would still prefer the normal risk chicken. These open-ended follow-ups were included to distinguish pure zero responses (i.e. people who were not willing to pay any extra premium for the safer chicken) from those willing to pay a low but non-zero premium.

Finally, those having stated a zero $\mathrm{WTP}^{11}$ were given a follow-up question in which they were provided an opportunity to elaborate on their response. This question was posed as an open-ended question and was included in order to enable the exclusion from subsequent analyses of all revealed protesters, i.e. people having stated a zero WTP for reasons other than a genuine indifference between the two goods. In the end we decided to include all respondents stating a zero WTP in the analysis, including the 15 that could be considered protesters. It is not clear how to deal with protesters and the motivation for including them is that they would "say no" if the projects were real (Carson and Hanemann, 2005).

\section{Empirical models}

The following three sections describe the empirical analysis. We first describe how the health variable was calculated. We then describe the non-parametric and then the parametric specifications we estimate.

\subsection{Health related quality of life}

All respondents were presented with the same information regarding probability, severity, and duration of the different health states related to getting salmonellosis. Hence, it is not possible to examine how respondents' WTP varies with the severity and duration of illness. Instead, we examine whether WTP is proportional to the change in the probability of getting salmonellosis and the expected loss in QALYs.

Based on the respondents' answers to how they perceived different health states, i.e. their current health level and the three specified health levels when sick (mild, moderate, and severe), we can estimate the respondents' expected QALY loss conditional on becoming ill ( $\triangle$ QALY). Hence, our estimates of $\triangle \mathrm{QALY}$ are conditional on being ill and the variation between respondents is a result of differences in the

\footnotetext{
${ }^{11}$ To qualify for this question, a respondent must have given a no-no response to the ordinary valuation questions in combination with a premium of zero in the follow-up question asking for the minimum premium at which the normal risk chicken would be preferred.
} 
perceived health loss if ill (which depends on the respondents' current health and perceived severity of the three health states if ill as assessed using the VAS scale). The total expected health loss conditional on being ill is therefore calculated as follows,

$$
\Delta \mathrm{QALY}_{i}=\sum_{j=1}^{3}\left(H_{i}-S_{i j}\right) q_{j} \frac{\text { days }_{j}}{365 \text { days } / \text { year }}+r_{i} H_{i} L_{i},
$$

where $H_{i}$ is the perceived current health level with the subscript referring to an individual $i, S_{i j}$ are individual $i$ 's perceived health levels for the three different health states, i.e. $j=\{$ mild, moderate, severe , and $q_{j}$ is the probability of health state $j$ when sick from salmonellosis. The last term, $r_{i} H_{i} L_{i}$, denotes the expected change in QALYs due to premature death with $r_{i}$ being the conditional mortality risk and $L_{i}$ the life expectancy, the latter being based on the age and gender of the respondent. ${ }^{12}$

In our statistical analysis, we divide the total expected QALY loss into two terms, corresponding to morbidity and mortality. Inserting the probabilities and durations of the three health states, the expected health loss related to the morbidity risk is calculated as,

$$
\Delta \mathrm{QALY}_{\text {morb }, i}=\left(H_{i}-S_{i, \mathrm{mild}}\right) 0.75 \frac{3}{365}+\left(H_{i}-S_{i, \mathrm{mod}}\right) 0.23 \frac{7}{365}+\left(H_{i}-S_{i, \mathrm{sev}}\right) 0.02 \frac{20}{365},
$$

whereas the equivalent for mortality risk is

$$
\Delta \mathrm{QALY}_{\text {mort }, i}=r_{i} H_{i} L_{i}
$$

\subsection{Non-parametric estimation}

Non-parametric estimation offers an advantage over parametric estimation since it does not rely on distributional assumptions made by the analyst. In this study we use Turnbull's lower bound (TB) estimator of WTP (Turnbull, 1976). ${ }^{13}$ It is a conservative estimator of WTP and of VSC with the aim of addressing the hypothetical nature of the respondents' answers which may lead to bias (Blumenschein et al., 2008).

Let $b_{j}$ and $F\left(b_{j}\right)$ denote the bid and the the proportion of no answers to the offered bid. The TB mean WTP is estimated by

$$
E_{T B}[W T P]=\sum_{j=0}^{J} b_{j}\left(F\left(b_{j+1}\right)-F\left(b_{j}\right)\right),
$$

where the bids are indexed from smallest $\left(b_{1}\right)$ to largest $\left(b_{J}\right), b_{0}=0$, and it is assumed that $F(0)=0$ and $F(\infty)=1$, i.e. no respondent has a negative or infinite WTP, and that $F\left(b_{j}\right)$ is weakly monotonically increasing. When $F\left(b_{j}\right)$ is non-monotonic, the pooled adjusted violators algorithm (PAVA) needs to be

\footnotetext{
${ }^{12}$ The last term assumes health will remain constant over the lifetime and hence overestimates the QALY loss from mortality, since health tends to decline with age.

${ }^{13}$ The Turnbull lower bound estimator is also known as the Kaplan-Meier estimator (Carson and Hanemann, 2005).
} 
used prior to estimation of Eq. (8) (Turnbull, 1976; Ayer et al., 1955). Equation (8) can be used for interval data when bid ranges are non-overlapping as in the SB elicitation format. The bid levels in our DB format result in bid ranges that are overlapping, however. We therefore have to use Turnbull's self consistency algorithm (TSCA). The TSCA divides the bids into non-overlapping "basic intervals" and allocates observations to each interval through an iterative process until the survival function converges (Bateman et al., 2002, pp. 232-237). ${ }^{14}$

\subsection{Parametric estimation}

The main purpose of the parametric estimation is to examine how different covariates influence WTP, not to examine the underlying structural model. Since the coefficient estimates of the bid-function approach show the marginal impact on WTP of different covariates (Cameron, 1988; Bateman et al., 2002), our parametric models are based on the bid-function approach (instead of the utility-function approach (Hanemann, 1984)).

We assume a multiplicative model. Taking logs results in the econometric model estimated,

$$
\begin{aligned}
\ln \left(W T P_{i}\right)= & \alpha+\beta_{1} \ln \left(\Delta p_{\text {morb }, i}\right)+\beta_{2} \ln \left(\Delta \mathrm{QALY}_{\text {morb }, i}\right)+\beta_{3} \ln \left(1+\frac{\Delta \mathrm{QALY}_{\text {mort }, i}}{\Delta \mathrm{QALY}_{\text {morb }, i}}\right) \\
& +\sum_{k=1}^{K} \gamma_{k} f_{k}\left(x_{i}\right)+\varepsilon_{i},
\end{aligned}
$$

where $f(x)$ defines dummy variables and the natural logarithm of continuous variables. ${ }^{15}$ Proportionality between WTP and a change in risk and QALYs implies $\beta_{1}=\beta_{2}=\beta_{3}=1$. Preliminary analysis showed that a normal distribution fits our logged data best, and we therefore estimate a log-normal model (Alberini, 1995).

\section{Results}

This section is divided into three main parts. We first present results from the survey based on descriptive statistics. Thereafter, we show our results from the non-parametric analysis and finally the results from the parametric analysis.

We enforced an exclusion rule based on survey comprehension, a decision that was based on two criteria: (i) if the respondent had stated a better health status conditional on getting salmonellosis than

\footnotetext{
${ }^{14}$ We used a conversion criterion equal to 0.005 .

${ }^{15}$ Equation (9) is based on the following relationship between WTP and changes in morbidity risk and QALYs,

$$
\begin{aligned}
W T P & =\Delta p_{\text {morb }}\left[\Delta \mathrm{QALY}_{\text {morb }}+\Delta \mathrm{QALY}_{\text {mort }}\right] \\
& =\left(\Delta p_{\text {morb }}\right)\left(\Delta \mathrm{QALY}_{\text {morb }}\right)\left[1+\frac{\Delta \mathrm{QALY}_{\text {mort }}}{\Delta \mathrm{QALY}_{\text {morb }}}\right]
\end{aligned}
$$
}


without (14 respondents), or (ii) if a respondent had given inconsistent answers to the double-bounded dichotomous choice WTP question (69 respondents).

In the first part of the survey, respondents were asked whether and if so how often they eat chicken. If they stated that they did not eat chicken they were asked to "value a food with similar characteristics as chicken". We found that about $5 \%$ never eat chicken. We considered dropping these respondents from the sample, but our analysis showed that including them had only minor effects on the quantitative results and no effect on the qualitative results. We therefore decided to include them in the final analysis.

\subsection{Descriptive statistics}

\subsubsection{Demographics, socio-economics, and perceived risk and health}

The description of the respondents and the general Swedish population is shown in Table 3. Most of the statistics are close to the corresponding values for the general population. The most obvious deviation regards gender, with $59 \%$ of respondents being female as compared to about $50 \%$ in the general population. In addition, the income level is somewhat higher and the household size is larger in our sample compared with the general population. All three of these differences may be explained in part by the sample being restricted to respondents in the age interval 18-74 years, as households with older individuals tend to have smaller incomes, no children in the household, and to be disproportionately female. In addition, women and those living in larger households may have greater interest in food safety.

[Table 3 about here.]

Table 4 tabulates descriptive statistics for some of the more material questions of the main survey. Respondents perceive the risk for annual food-related illness quite accurately; the mean assessment, approximately 9 per 100 citizens, is consistent with the true frequency being in the range $8-11$ cases per 100 citizens (SLV, 1994; SoS, 2001). Females perceive the risk to be higher than males, a difference that is statistically significant (5 percent level). Question Q3 was included to determine risk perception abilities. Whereas 24 percent of the respondents correctly ranked the risk of dying from five different causes $^{16}$ (including food contamination), more than 50 percent accurately ranked food contamination as the least deadly of the risks.

The mean VAS estimates of current health status (Q19) are almost identical to results in several other Swedish studies (Koltowska-Häggström et al., 2007; Andersson, 2007; Brooks et al., 1991). Additionally, respondents were asked to rank the three different variants of salmonellosis (mild, moderate and severe)

\footnotetext{
${ }^{16}$ These were cardio-vascular diseases, lung cancer, car accidents, AIDS/HIV and food contamination.
} 
on the VAS. These estimated values are somewhat more difficult to compare with other results, since the definitions of symptoms and illness duration may vary considerably between studies. Mauskopf and French (1991), whose definitions of the illness states are similar to ours, reported values for mild, moderate and severe salmonellosis where the baseline health-state was "perfect health at the time of exposure" (p. 623). Following Mauskopf and French and assuming that respondents would have perfect health, re-normalizing our estimates so that current health $=100$, we obtain 71,52 , and 31 for mild, moderate, and severe salmonellosis, which can then be compared to 77, 60 and 31 in Mauskopf and French (1991).

[Table 4 about here.]

\subsubsection{Self-assessed knowledge of food safety}

In one of the survey questions, respondents were asked to state their self-perceived knowledge about issues related to food safety. Typically, more respondents considered their own knowledge to be above average $(33 \%)$ rather than below average $(12 \%)$. Table 5 cross-tabulates the stated knowledge by the responses to some related survey questions. Some interesting aspects may be noted. First, those asserting an extensive knowledge of food safety scored higher in Q3 when ranking all death causes, but they did not score better on ranking food safety correctly as the least likely death cause. The group with limited knowledge did have the lowest score, thus we found some weak evidence that self-perceived knowledge is able to predict risk perception ability to some degree. Differences between the groups are small, though.

Judging one's knowledge as extensive also seems to imply placing an appreciably higher value on food safety as compared to the price of food (see Q5) than the sample as a whole. This may seem somewhat counter-intuitive, considering the fact that respondents with a self-perceived limited knowledge perceive the risk of foodborne illness to be higher than others do, and thus should, ceteris paribus, place a higher value on food safety relative to the price. However, this seeming contradiction may be explained: (i) by those who value safety actively seeking knowledge on food safety, or (ii) at least partly, by the fact that those having stated a limited knowledge also have a smaller mean income per consumption unit (i.e. taking into account household size and age composition), and might therefore value a low price relatively higher compared to other food attributes than other groups. Moreover, respondents stating a higher degree of knowledge also estimate their own risk of contracting food-borne infectious intestinal disease as lower than the rest of the sample (Q14). Assuming the degree of self-assessed knowledge to be correct, this would be a natural conclusion, since many preventive measures to avoid food-borne illnesses are rather straightforward to implement (like hygiene) once you know about them. 
[Table 5 about here.]

\subsection{WTP distribution and non-parametric analysis}

In this section we provide estimates and distributions of mean WTP and VSI based on the respondents' choices. Point estimates are based on the TB non-parametric measures discussed above, while the distributions are assessed using Monte Carlo simulation procedures. ${ }^{17}$

\subsubsection{Distribution of responses}

The numbers of respondents in each of the 60 groups ${ }^{18}$ as well as the proportion rejecting the proposed bid (in the first round of yes/no responses) are summarized in Table 8 in the appendix (on-line). Notably, in some combinations of morbidity risk and mortality risk reduction, the percentage of the sample rejecting the proposed bid does not increase monotonically with the bid level as would be predicted by economic theory. As discussed above, the remedy for this violation is to pool adjacent non-compliant bid levels and to recalculate choice measures and dispersion parameters based on the new sample distribution.

Apart from this procedural modification, we also want to analyze whether the relation between proposed bid and response is in accordance with what we would expect from economic theory. For this purpose a chi-squared test $\left(\chi_{(4)}^{2}\right)$ of this interdependence was performed for each of the twelve risk reduction combinations. The null hypothesis for this test is that the distribution of yes/no responses is independent of the bid level. Interestingly, rejecting the null hypothesis seems to be negatively correlated with the mortality risk reduction size, with rejections at the $1 \%$ level for the lowest risk levels $(0$ and 6 in 100 million), except for one subgroup, but with three non-rejections at the highest level (12 in 100 million), respectively. Thus it seems that introducing mortality risk in the decision process makes it increasingly difficult for respondents to discriminate between the different bid levels. We return to this point in our discussion below.

\subsubsection{Estimation of mean WTP}

Turnbull non-parametric estimates of mean WTP for each of the 12 different combinations of mortality risk and morbidity risk in the survey are summarized in Table 9 in the appendix (on-line). A graphical presentation provides a better understanding of the main results and we report them here as Figures 1 and 2. The figures (and the table) include estimates for both the SB and the DB formats as described above.

\footnotetext{
${ }^{17}$ In these simulations, which were based on 100000 iterations each, both the number of respondents in each subsample as well as the mean and variance of each E(WTP) estimation were accounted for. In this way a combined distribution for VSI was possible to simulate for the entire sample and for each of the two formats (Turnbull SB and DB). The simulations were performed using RiskAMP ${ }^{\complement}$, which is an add-in to Microsoft Excel ${ }^{\circledR}$.

${ }^{18}$ There were 60 combinations of mortality risks, morbidity risks and bid amounts.
} 
Normally, there would be at least two hypotheses one would expect these WTP values to comply with regarding the morbidity risk, based on theoretical considerations. First, ceteris paribus, one would expect WTP to be a positive function of the risk reduction (weak scope sensitivity). Second, for sufficiently small risk reductions, WTP should be approximately a linear function of risk reductions (Hammitt and Graham, 1999) so that WTP should change nearly proportionately with the risk reduction size (strong scope sensitivity). However, the TB estimators will not necessarily adhere to this criterion even theoretically. ${ }^{19}$ Hence, when using TB we cannot use proportionality of WTP to risk reduction as a validity test, which implies that we focus entirely on the weak scope sensitivity requirement here (proportionality is tested in the parametric models).

Moreover, since the WTP question, in addition to the morbidity risk, also covered a mortality risk, there are two additional requirements on WTP that generally have to be met if the weak scope sensitivity criterion is to be satisfied. First, we would expect that holding the mortality risk reduction constant and increasing the morbidity risk reduction would lead to an increase in WTP. Second, and similarly, the weak sensitivity criterion suggests that holding the morbidity risk reduction constant while increasing the mortality risk reduction should generate a higher mean WTP.

The findings from the survey reveal mixed results. Focusing on the SB format shown in Figure 1, we find no evidence suggesting that mean WTP is increasing with mortality risk. However, the reduction in mortality risk is very small and incremental WTP may be too small to detect. The largest reduction in mortality risk in any scenario is 9 in 100 million. Using a large estimate of VSL of SEK 80 million (Hultkrantz and Svensson, 2012), WTP to reduce the mortality risk is about SEK 7.2. Regarding sensitivity to scope for the morbidity risk, we find only for those respondents where mortality risks are absent (that is, where we have a 0 in 100 million baseline mortality risk) a mean WTP that is increasing monotonically with the size of the morbidity risk reduction.

[Figure 1 about here.]

The findings from the DB format reveal a mean WTP for those respondents being presented with a 0 mortality risk that is weakly increasing with the size of the morbidity risk reduction, i.e. mean WTP of $\Delta p_{\text {morb }}=3$ is statistically significantly larger than the corresponding value for $\Delta p_{\text {morb }}=1$ at the 5 percent level $(\mathrm{p}$-value $=0.04)$, and larger than for $\Delta p_{m o r b}=2$ at the 10 percent level $(\mathrm{p}$-value $=0.057)$. (Mean WTP for $\Delta p_{\text {morb }}=1$ and 2 are not significantly different.) When respondents were also presented with a positive mortality risk, mean WTP either followed a U-shape or inverted U-shape. Moreover, the DB format also produced results that suggest mean WTP is not increasing with the mortality risk. These

\footnotetext{
${ }^{19}$ This follows because the TB lower bound is not an unbiased estimate of the mean.
} 
results suggest, as in the previous section, that the inclusion of the mortality risk makes it increasingly difficult to respond to the WTP question, resulting in answers that are not in line with the theoretical predictions.

[Figure 2 about here.]

\subsubsection{Value of a statistical illness}

Based on the results above which suggested that individuals find it difficult to respond to questions that ask them about their WTP for a reduction in both the risk of illness and death we do not report any VSL estimates. Instead we focus on the respondents' preferences for a reduction in the risk of illness, i.e. the estimation of VSI. Since we have finite risk reductions, the VSI is estimated according to Eq. (3) by dividing the mean WTP by the morbidity risk reduction facing the various subsamples. Our preferred VSI is calculated with the median morbidity risk reduction (2 in 10 000). In order to minimize the possible effects of respondents confounding the two different types of risk reductions, calculations were performed only for subsamples that were presented with a zero mortality baseline risk.

Our preferred estimates of VSI are shown in Table 6. The estimated VSI point values for a case of salmonellosis are SEK 103000 and SEK 139000 for the SB format and the DB format, respectively. Of these values, the SB estimates are preferred, because of the scope insensitivity of the DB format discussed earlier, and the issue that the second answer in the DB format may be influenced by the answer to the first question (Watson and Ryan, 2007). The distribution, which is based on Monte Carlo simulations, for the two formats of the VSI is also illustrated in Figure 3.

[Table 6 about here.]

[Figure 3 about here.]

Calculations of the VSI for salmonellosis (or other similar diseases) are scarce in the literature, and none has previously been carried out in Sweden. Internationally, two relevant studies have been found. In the United Kingdom, Henson (1996) used a CVM study to calculate a VSI of salmonellosis following chicken consumption of US\$ 19500 in 2006 price level, which is close to the estimates obtained in this study (US\$ 14000 and 18900 using the SB and DB format). ${ }^{20}$ In the United States, Hammitt and Haninger (2007) used a stated preference study to calculate VSI of "foodborne illness" with symptoms similar to those used in this study. They found that households without children were willing to pay, on average, between US\$ 8300 and 16100 for a statistical case, while households with children were

\footnotetext{
${ }^{20}$ Average exchange rates 2006, £ $1=$ US $\$ 1.840$ and SEK $1=$ US\$ 0.136 (http://www.riksbank.se, 2011-10-27) and UK consumer price index (CPI) for 1993-2006, 1.246 (stats.oecd.org, 2011-10-27).
} 
prepared to pay slightly more, between US\$ 10800 and 16400 (in 2004 price level). Their values are in general somewhat lower than the values in this study, but differences regarding severity (e.g., the chance of needing to see a doctor) and duration of illness may account for most of these differences.

\subsubsection{WTP per QALY}

Following the approach above we can also estimate a WTP per QALY based on the TB estimates. To estimate the WTP per QALY information about mean WTP (E[WTP]), the change in morbidity risk $\left(\Delta p_{\text {morb }}\right)$, and change in QALYs from being sick or dead $\left(\triangle \mathrm{QALY}_{\text {morb }}\right.$ and $\left.\triangle \mathrm{QALY}_{\text {mort }}\right)$, should be used as follows,

$$
\mathrm{WTP}_{\mathrm{QALY}}=\frac{\mathrm{E}[\mathrm{WTP}]}{\Delta p_{\text {morb }} \times\left(\Delta \mathrm{QALY}_{\text {morb }}+\Delta \mathrm{QALY}_{\text {mort }}\right)} .
$$

Thus, the change in morbidity risk is given by the survey design and in line with our analysis above we restrict our calculation to a change equal to 2 in 10 000, whereas the two other variables are given by the survey results. Moreover, in line with our analysis above we only use the mean estimates of WTP with a zero mortality risk. This means that $\triangle \mathrm{QALY}_{\text {mort }}$ is equal to zero in our estimation of Eq. (10). ${ }^{21}$

Our preferred estimate based on the SB format is shown in Table 6. The level of the WTP per QALY found in this study (US\$ 3.3 million) is much higher than the values for policy evaluation used by health authorities in the UK and USA, which are in the ranges £20 000-30 000 and US\$ 50 000-100 000 (Shiroiwa et al., 2010). It is also higher than other studies trying to estimate the WTP per QALY. For instance Gyrd-Hansen (2003) and Pinto-Prades et al. (2009) who used approaches where respondents were directly asked about their WTP for a health gain found higher end estimates of US\$16 200 and US $\$ 98600 .^{22}$ Haninger and Hammitt (2011) used a similar analysis as ours and due to a non-proportional WTP they found estimates in the range US\$ $156000-5587000$ in 2004 price level. The estimators in our study and Haninger and Hammitt (2011) differ, non-parametric lower bound in ours and parametric medians in theirs, but both studies find that the ex ante approach can produce very high estimates of WTP per QALYs compared to both policy values and ex post approaches.

\subsection{Parametric analysis}

Using parametric analysis, we can examine the effects from various socioeconomic and other variables. Our regression models are based on the bid-function approach as discussed in the methods section and,

\footnotetext{
${ }^{21}$ Since WTP was found not to be sensitive to the size of the mortality risk reduction, WTP per QALY would drop significantly if we also took into account the mortality risk; the effect on the numerator would be marginal whereas the denominator would increase significantly.

${ }^{22}$ Average exchange rates 2006, DKK $1=$ US $\$ 0.168$ and $€ 1=$ US $\$ 1.255$ (http://www.riksbank.se, 2011-10-27) and the Danish CPI for 2001-2006, 1.097 (stats.oecd.org, 2011-10-27). Pinto-Prades et al. (2009) examined the proportionality of the WTP to the change in QALY, and order effects. Since they found both order effects and that WTP was not proportional to duration, change in QALY, and the risk reduction, they have a large variation in their reported values. (No information on which year values refer to in Pinto-Prades et al. (2009).)
} 
following the previous results, we focus on the SB format. ${ }^{23}$ Table 7 shows the regression results for three models; Model 1 includes only variables for the reduction in the probability of illness and changes in QALYs, Model 2 adds demographic and socio-economic variables, and Model 3 also adds variables defining behavior and perception related to food safety.

[Table 7 about here.]

In Model 1 we find the expected results that WTP is positively related to the size of the change in the morbidity risk $\left(\ln \left(\Delta p_{\text {morb }}\right)\right)$ and the morbidity QALY change $(\ln (\Delta \mathrm{QALY}$ morb $))$. We do not find any statistical relationship between WTP and the variable for a change in QALYs related to the mortality risk $\left(\ln \left(1+\Delta \mathrm{QALY}_{\text {mort }} / \Delta \mathrm{QALY}_{\text {morb }}\right)\right)$. This contradicts our theoretical expectations but is consistent with the results of the non-parametric analysis which revealed difficulties for respondents when the mortality risk was included in the scenario (an alternative analysis substituting one variable representing the change in QALYs including both morbidity and mortality risk for the two $\triangle$ QALY variables in Model 1 resulted in a positive but statistically insignificant coefficient estimate). Regarding proportionality we find that the estimated coefficients on $\ln \left(\Delta p_{\text {morb }}\right)$ and $\ln (\Delta \mathrm{QALY}$ morb $)$ are much smaller than one, and thus, WTP does not appear to be proportional to either. We cannot, however, reject the hypothesis that the coefficient on $\ln \left(\Delta p_{\text {morb }}\right)$ is equal to one, i.e. we cannot reject that WTP is indeed proportional to the change in morbidity risk in Model 1.

Including the demographic and socio-economic variables in Model 2 has only minor effects on the coefficient estimates for $\ln \left(\Delta p_{\text {morb }}\right)$ and $\ln \Delta \mathrm{QALY}$ morb. The former is no longer statistically significant, though. Among the variables describing individual characteristics we find that WTP is positively correlated with income level, being a female, age, and household size. Income is expected to have a positive impact on WTP for two reasons. First, the potential utility loss from illness seems likely to be greater the wealthier the individual. Second, spending a specific amount causes less utility loss due to diminishing marginal utility of income. Female respondents have been found to be willing to pay somewhat more for food safety than men in some studies, but the empirical evidence is inconclusive (Hammitt and Haninger, 2007; Haninger and Hammitt, 2011; Buzby et al., 1995). The general predicted effect from age is largely indeterminate (Hammitt, 2005). Our results suggest that older respondents are willing to pay more to reduce their salmonella risk. The significantly positive effect of household size is somewhat stronger than in other studies (Hammitt and Haninger, 2007; Haninger and Hammitt, 2011; Buzby et al., 1995). Respondents were asked to assume that only they would consume the chicken, not anyone else in the household. The positive relationship may therefore suggest that respondents' WTP also reflects

\footnotetext{
${ }^{23}$ Regression results for the DB format available upon request from the authors.
} 
their concern for the safety of others. For instance, household size works as a close proxy for the number of children in the household and WTP for protecting one's children has been shown to be higher than for one self (Andersson and Lindberg, 2009; Hammitt and Haninger, 2007, 2010). However, the positive relationship between WTP and household size could also reflect the respondent's concern about his/her children's wellbeing if he/she gets sick, since he/she would not be able to properly take care of them during the illness. We find no evidence that WTP is influenced by the respondents' education level. We expected a negative relationship, if any. Individuals with a higher educational level may have better information about food contamination and would thus be less concerned about the risk of suffering from such illness (Henson, 1996).

Adding the variables defining behavior and perception related to food safety in Model 3 changes some of the results from Model $2 ; \ln \left(\Delta p_{\text {morb }}\right)$ is again statistically significant while $\ln ($ Income $)$ and $\ln ($ Age $)$ also become statistically insignificant. ${ }^{24}$ Among the new variables included we find that eating chicken (a dummy variable coded to 1 if respondent eats chicken) is negative and significant, suggesting that those who do not eat chicken (and who were asked to "value a food with similar characteristics as chicken") have a higher WTP than those who do eat chicken. A plausible explanation might be that at least some of the respondents who did not eat chicken, did so partly because of its well-known association with food-related illnesses. Those respondents would thus assign a higher value on avoiding food-related illnesses than average consumers, which would account for the negative sign found. Moreover, concern about food-related illnesses when shopping and ranking safety higher than price both have the expected positive signs, and are both significant. Reading descriptions on food labels indicates a more general awareness of and interest in nutrition and health related to food than the concern variable, though this is statistically insignificant. Finally, respondents' perception of their risk being different from the average risk (Lower risk and Higher risk) does not influence the WTP, which implies that respondents accepted the risk levels presented to them in the survey.

To estimate a VSI based on the parametric analysis we use the results from Model 1. We follow the recommendations for a conservative estimate of respondents' WTP and present as our preferred VSI from the parametric analysis the median instead of the mean WTP (Haab and McConnell, 2003). Our median estimate is calculated using the mean of the covariates of Model 1 except for $\left(\ln \left(\Delta p_{\text {morb }}\right)\right)$ for which we use the median change in risk equal to 2 in 10 000. Our calculations provide a median VSI equal to SEK 130000 (95\% CI: 87 000-188 000) (US\$ 17 700), similar to the results in Table 6 using

\footnotetext{
${ }^{24}$ Our weak income effect is consistent with findings in the literature. An insignificant relationship between WTP and income has been found in studies of food safety (Buzby et al., 1995; van der Pol et al., 2003) and may reflect the low costs often involved when reducing the food risk (Haninger and Hammitt, 2011).
} 
the Turnbull estimator. ${ }^{25}$

\section{Discussion}

This is the first Swedish SP study where the WTP for food safety has been estimated. We have used the results from a Swedish CVM survey to estimate the mean and median WTP and VSI for a reduction of the risk of getting salmonellosis as a consequence of chicken consumption. We have made an extensive analysis of the relationship between WTP, the size of the risk reduction, and QALYs, which contributes to the understanding of valuing small and compound health risk reductions.

We estimate that, depending on the risk reduction presented, people are willing to pay a premium of between SEK 13-39 per kilo for a chicken product that reduces the risk of getting salmonellosis by between 1 and 3 in 10 000. This corresponds to a price increase of approximately 10 to 30 percent. Our preferred lower-bound mean and median VSI from the non-parametric and parametric analysis are SEK 103000 (US\$ 14 000) and SEK 130000 (US\$ 17 700), respectively. These values seem implausibly large, but they are comparable to estimates obtained in a UK study (Henson, 1996) and slightly higher than estimates obtained in U.S. studies (Hammitt and Haninger, 2007; Haninger and Hammitt, 2011). One reason for these large estimates is that these studies elicit WTP for very small changes in the risk of illness. Estimated WTP is small (a few dollars or less), but the risk reduction is so small that the VSI is very large. A study using a much larger risk reduction or an ex post scenario would yield smaller estimates of VSI. However, our estimates related to mortality risks are not valid estimates of the respondents' preferences, so we do not report any VSL estimates from this study. As noted above, the reductions in mortality risk presented in our survey are so small that incremental WTP to reduce mortality risk may be too small to measure.

We found weak evidence of scope sensitivity. The non-parametric analysis suggests a monotonic relationship between WTP and the magnitude of the morbidity risk reduction when the mortality risk is equal to zero, but non-monotonic when respondents are also presented with a positive mortality risk. In the parametric analysis we find a positive relationship where the size of the coefficient estimate is consistent with previous findings in the literature, i.e. positive but less than one. Our estimate is fairly stable between our three regressions, but only statistically significant in two of them. Overall our results show a weak relationship between WTP and risk reduction. One reason why we do not find a stronger relationship could be the small variation in the risk levels, which translates into a small variation in the differences in risk changes between the scenarios. When the survey was developed one objective was to

\footnotetext{
${ }^{25}$ Mean VSI equal to SEK 411000 (95\% CI: 275 000-591 000) (US\$ 55 900). Confidence intervals estimated using bootstrap technique.
} 
create a realistic scenario. Choosing risk levels close to the actual ones at the time of the survey may have increased realism, but may have increased the difficulty for respondents to distinguish between them.

A contribution of this paper is the analysis of the WTP per QALY. We found a strong relationship between WTP and the size of the QALY change related to a non-fatal outcome. We could, however, reject that it was proportional. This result is consistent with previous theoretical (Hammitt, 2013) and empirical findings (Pinto-Prades et al., 2009; Haninger and Hammitt, 2011). We did not find any statistically significant relationship between WTP and a change in QALYs related to mortality risk. This is contrary to our expectations and could be a result of the very small mortality risk presented to the respondents, less than or equal to 12 per 100 million, and also that the cognitive task of evaluating both a morbidity and mortality risk was too difficult for the respondents. Presenting respondents with information on both morbidity and mortality in the same choice set might have exaggerated the salience of the mortality risk in the minds of our respondents. Regarding the monetary estimates of a WTP per QALY we find significantly higher values than those used by policy makers and estimates from some recent studies in other high-income countries (Shiroiwa et al., 2010; Gyrd-Hansen, 2003; Pinto-Prades et al., 2009), but within the range of estimates from a recent U.S. study using a similar survey design as ours (Haninger and Hammitt, 2011).

Our high estimates of a WTP per QALY suggest that the framing of the risk scenario to elicit individuals' preferences for gains in QALYs has important policy implications. In our study we chose an ex ante scenario, i.e. the respondents faced a risk of illness with an uncertain severity. This is a relevant scenario for many health risks including food safety. Haninger and Hammitt (2011) also used an ex ante approach and found similar qualitative results. However, eliciting the WTP per QALY based on an ante scenario is difficult, since respondents will have to evaluate the combination of the risk of becoming sick and also the outcome of the illness.

In addition to the estimate of VSI the main contribution of this study is methodological. The aim of the study was to estimate the VSI, VSL, and WTP per QALY based on answers from a CVM study. Our results suggest that we may have had too much confidence in how much respondents can cope with in an SP study. We know from previous research that individuals find it hard to evaluate small probabilities. In this study respondents were asked to evaluate one risk reduction and the distribution of different health states if getting salmonellosis, and in addition some subsamples were presented with an additional mortality risk. As described above we found a WTP increasing with the size of the risk reduction only among those respondents who were not presented with the mortality risk, which suggests that the evaluation of two risk changes may have been too challenging to our respondents. 


\section{References}

Alberini, A.: 1995, 'Efficiency vs Bias of Willingness-to-Pay Estimates: Bivaraite and Interval-Data Models'. Journal of Environmental Economics and Management 29, 169-180.

Andersson, H.: 2007, 'Willingness to Pay for Road Safety and Estimates of the Risk of Death: Evidence from a Swedish Contingent Valuation Study'. Accident Analysis and Prevention 39(4), 853-865.

Andersson, H., J. K. Hammitt, G. Lindberg, and K. Sundström: 2013, 'Willingness to Pay and Sensitivity to Time Framing: A Theoretical Analysis and an Application on Car Safety'. Environmental and Resource Economics 56(3), 437-456.

Andersson, H. and G. Lindberg: 2009, 'Benevolence and the value of road safety'. Accident Analysis 86 Prevention 41(2), 286-293.

Andersson, H. and N. Treich: 2011, 'The Value of a Statistical Life', In: de Palma, A., Lindsey, R., Quinet, E. and Vickerman, R. (Eds.), A Handbook of Transport Economics, Edward Elgar, Cheltenham, UK, pp. 396-424.

Antle, J. M.: 1995, Choice and Efficiency in Food Safety Policy. Washington, DC, USA: The AEI Press.

Ayer, M., H. D. Brunk, G. M. Ewing, W. T. Reid, and E. Silverman: 1955, 'An Empirical Distribution Function for Sampling with Incomplete Information'. Annals of Mathematical Statistics 26(4), 641647.

Bateman, I. J., R. T. Carson, B. Day, M. Hanemann, N. Hanley, T. Hett, M. Jones-Lee, G. Loomes, S. Mourato, Özdemiroḡlu, D. W. Pearce, R. Sugden, and J. Swanson: 2002, Economic Valuation with Stated Preference Techniques: A Manual. Cheltenham, UK: Edward Elgar.

Bleichrodt, H. and M. Johannesson: 1997, 'Standard gamble, time trade-off and rating scale: experimental results on the ranking properties of QALYs'. Journal of Health Economics 16, 155-175.

Blumenschein, K., G. C. Blomquist, M. Johannesson, N. Horn, and P. Freeman: 2008, 'Eliciting Willingness to Pay without Bias: Evidence from a Field Experiment'. Economic Journal 118(525), $114-137$.

Brooks, R. G., S. Jendteg, B. Lindgren, U. Persson, and S. Björk: 1991, 'EuroQol: Health-Realted Quality of Life Measurement. Results of the Swedish Questionnaire Exercise'. Health Policy 18, 3748.

Buzby, J., J. Skees, and R. Ready: 1995, 'Using contingent valuation to value food safety: A Case Study of grapefruit and pesticide residues', In: Caswell, J.A. (Ed.), Valuing Food Safety and Nutrition, Boulder, CO, USA: Westview Press, pp. 219-256.

Cameron, T. A.: 1988, 'A New Paradigm for Valuing Non-market Goods Using Referendum Data: Maximum Likelihood Estimation by Censored Logistic Regression'. Journal of Environmental Economics and Management 15, 355-379.

Carson, R. T. and T. Groves: 2007, 'Incentive and informational properties of preference questions'. Environmental and Resource Economics 37, 181-210.

Carson, R. T. and W. M. Hanemann: 2005, 'Contingent Valuation', In: Mäler, K.-G. and Vincent, J. R. (Eds.), Handbook of Environmental Economics: Valuing Environmental Changes, Vol. 2 of Handbook in Economics, North-Holland, Amsterdam, the Netherlands, first edition, pp. 821-936.

Corso, P. S., J. K. Hammitt, and J. D. Graham: 2001, 'Valuing Mortality-Risk Reduction: Using Visual Aids to Improve the Validity of Contingent Valuation'. Journal of Risk and Uncertainty 23(2), 165184 .

EuroQol Group: 1990, 'A New Facility for the Measurement of Health-Related Quality of Life'. Health Policy 16, 199-208. 
Feeny, D., W. Furlong, G. Torrance, C. Goldsmith, Z. Zhu, S. DePauw, M. Denton, and M. Boyle: 2002, 'Multiattribute and singleattribute utility functions for the Health Utilities Index Mark 3 System'. Medical Care 40, 113-128.

French, M. T. and J. A. Mauskopf: 1992, 'A quality-of-life method for estimating the value of avoided morbidity'. American Journal of Public Health 82, 1533-1555.

Golan, E., J. Buzby, S. Crutchfield, P. Frenzen, F. Kuchler, K. Ralston, and T. Roberts: 2005, 'The Value to Consumers of Reducing Foodborne Risks', In: Hoffmann, S.A. and Taylor, M.R. (Eds.), Toward Safer Food - Perspectives on Risk and Priority Setting, Washington, DC, USA: RFF Press, pp. 129-158.

Gyrd-Hansen, D.: 2003, 'Willingenss to pay for a QALY'. Health Economics 12, 1049-1060.

Haab, T. C. and K. E. McConnell: 2003, Valuing Environmental and Natural Resources: The Econometrics of Non-Market Valuation. Cheltenham, UK: Edward Elgar.

Hammitt, J.: 2005, 'Willingness-to-Pay Measures of Food Safety Regulatory Benefits', In: Hoffmann, S.A. and Taylor, M.R. (Eds.), Toward Safer Food - Perspectives on Risk and Priority Setting, Washington, DC, USA: RFF Press, pp. 241-260.

Hammitt, J. K.: 2000, 'Evaluating Contingent Valuation of Environmental Health Risks: The Proportionality Test'. AERE (Association of Environmental and Resource Economics) Newsletter 20(1), $14-19$.

Hammitt, J. K.: 2002, 'QALYs Versus WTP'. Risk Analysis 22(5), 985-1001.

Hammitt, J. K.: 2013, 'Admissible utility functions for health, longevity, and wealth: integrating monetary and life-year measures'. Journal of Risk and Uncertainty 47, 311-325.

Hammitt, J. K. and J. D. Graham: 1999, 'Willingness to Pay for Health Protection: Inadequate Sensitivity to Probability?'. Journal of Risk and Uncertainty 18(1), 33-62.

Hammitt, J. K. and K. Haninger: 2007, 'Willingness to Pay for Food Safety: Sensitivity to Duration and Severity of Illness'. American Journal of Agricultural Economics 89(5), 1170-1175.

Hammitt, J. K. and K. Haninger: 2010, 'Valuing fatal risks to children and adults: Effects of disease, latency, and risk aversion'. Journal of Risk and Uncertainty 40, 57-83.

Hanemann, M. W., J. Loomis, and B. Kanninen: 1991, 'Statistical Efficiency of Double-Bounded Dichotomous Choice Contingent Valuation'. American Journal of Agricultural Economics 73(4), 1255-1263.

Hanemann, W. M.: 1984, 'Welfare Evaluations in Contingent Valuation Experiments with Discrete Responses'. American Journal of Agricultural Economics 66(3), 332-341.

Haninger, K. and J. K. Hammitt: 2011, 'Diminishing Willingness to Pay per Quality-Adjusted Life Year: Valuing Acute Foodborne Illness'. Risk Analysis 31(9), 1363-1380.

Henson, S.: 1996, 'Consumer Willingness to Pay for Reductions in the Risk of Food Poisoning in the UK'. Journal of Agricultural Economics 47, 403-420.

Horowitz, J. K. and K. E. McConnell: 2002, 'A Review of WTA/WTP Studies'. Journal of Environmental Economics and Management 44, 426-447.

Hultkrantz, L. and M. Svensson: 2012, 'The value of a statistical life in Sweden: A review of the empirical literature'. Health Policy 108(2-3), 302-310.

Johannesson, M.: 1995, 'The Relationship Between Cost-Effectiveness Analysis and Cost-Benefit Analysis'. Social Science and Medicine 41(4), 483-489. 
Koltowska-Häggström, M., B. Jonsson, D. Isacson, and K. Bingefors: 2007, 'Using EQ-5D To Derive Utilities For The Quality Of Life - Assessment Of Growth Hormone Deficiency In Adults (QoL-AGHDA)'. Value in Health 10(1), 73-81.

Mason, H., M. Jones-Lee, and C. Donaldson: 2009, 'Modelling the Monetary Value of a QALY: A New Approach Based on UK Data'. Health Economics 18, 933-950.

Mauskopf, J. A. and M. T. French: 1991, 'Estimating the Value of Avoiding Morbidity and Mortality from Foodborne Illness'. Risk Analysis 11, 619-631.

Pinto-Prades, J., G. Loomes, and R. Brey: 2009, 'Trying to estimate a monetary value for the QALY'. Journal of Health Economics 28, 553-562.

Pliskin, J. S., D. S. Shepard, and M. C. Weinstein: 1980, 'Utility Functions for Life Years and Health Status'. Operations Research 28(1), 206-224.

Pratt, J. W. and R. J. Zeckhauser: 1996, 'Willingness to Pay and the Distribution of Risk and Wealth'. Journal of Political Economy 104(4), 747-763.

Rosen, S.: 1988, 'The Value of Changes in Life Expectancy'. Journal of Risk and Uncertainty 1(3), 285-304.

Shiroiwa, T., Y. Sung, T. Fukuda, H. Lang, S. Bae, and K. Tsutani: 2010, 'International Survey on Willingness-to-pay (WTP) for one Additional QALY gained: What is the Threshold of Cost Effectiveness?'. Health Economics 19, 422-437.

Simon, H.: 1990, 'A mechanism for social selection and successful altruism'. Science 250(4988), 16651668.

SJV: 2007, 'Översyn av salmonellakontrollprogrammet - en färdplan'. Report 2007:10, Swedish Board of Agriculture. (in Swedish).

SLV: 1994, 'Matförgiftningar i Sverige - resultat av en intervjuundersökning'. Report 41/94, National Food Administration. (in Swedish).

SoS: 2001, 'Nationella miljöhälsorapporten 2001'. National Board of Health and Welfare. (in Swedish).

Tolley, G., D. Kenkel, and R. Fabian (eds.): 1994, Valuing Health for Policy: An Economic Approach. Chicago, IL, USA: University of Chicago Press.

Tunçel, T. and J. K. Hammitt: 2014, 'A New Meta-Analysis on the WTP/WTA Disparity'. Journal of Environmental Economics and Management 68, 175-187.

Turnbull, B. W.: 1976, 'The Empirical Distribution Function with Arbitrarily Grouped, Censored, and Truncated Data'. Journal of the Royal Statistical Society 38(B), 290-295.

van der Pol, M., M. Ryan, and C. Donaldson: 2003, 'Valuing Food Safety Improvements using Willingness-to-Pay'. Applied Health Economics and Health Policy 2(2), 99-107.

Viscusi, W. K.: 2010, 'The heterogeneity of the value of statistical life: an introduction and overview'. Journal of Risk and Uncertainty 40, 1-13.

Viscusi, W. K. and J. E. Aldy: 2003, 'The Value of a Statistical Life: A Critical Review of Market Estimates Throughout the World'. Journal of Risk and Uncertainty 27(1), 5-76.

Watson, V. and M. Ryan: 2007, 'Expolring preference anomalies in double bounded contingent valuation'. Journal of Health Economics 26, 463-482.

Weinstein, M. C., D. S. Shepard, and J. S. Pliskin: 1980, 'The Economic Value of Changing Mortality Probabilities: A Decision-Theoretic Approach'. Quarterly Journal of Economics 94(2), 373-396. 
Figure 1: Mean WTP based on Turnbull lower bound estimator: Single bounded format

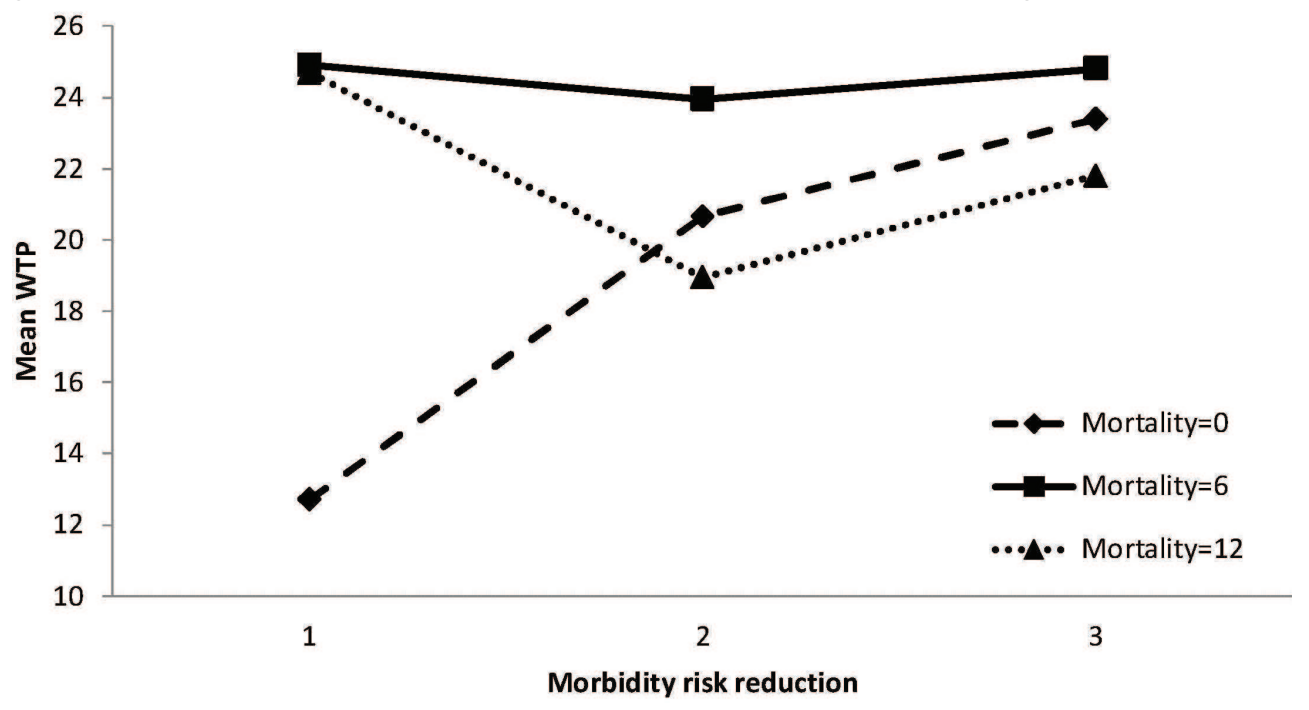

Figure 2: Mean WTP based on Turnbull lower bound estimator: Double bounded format

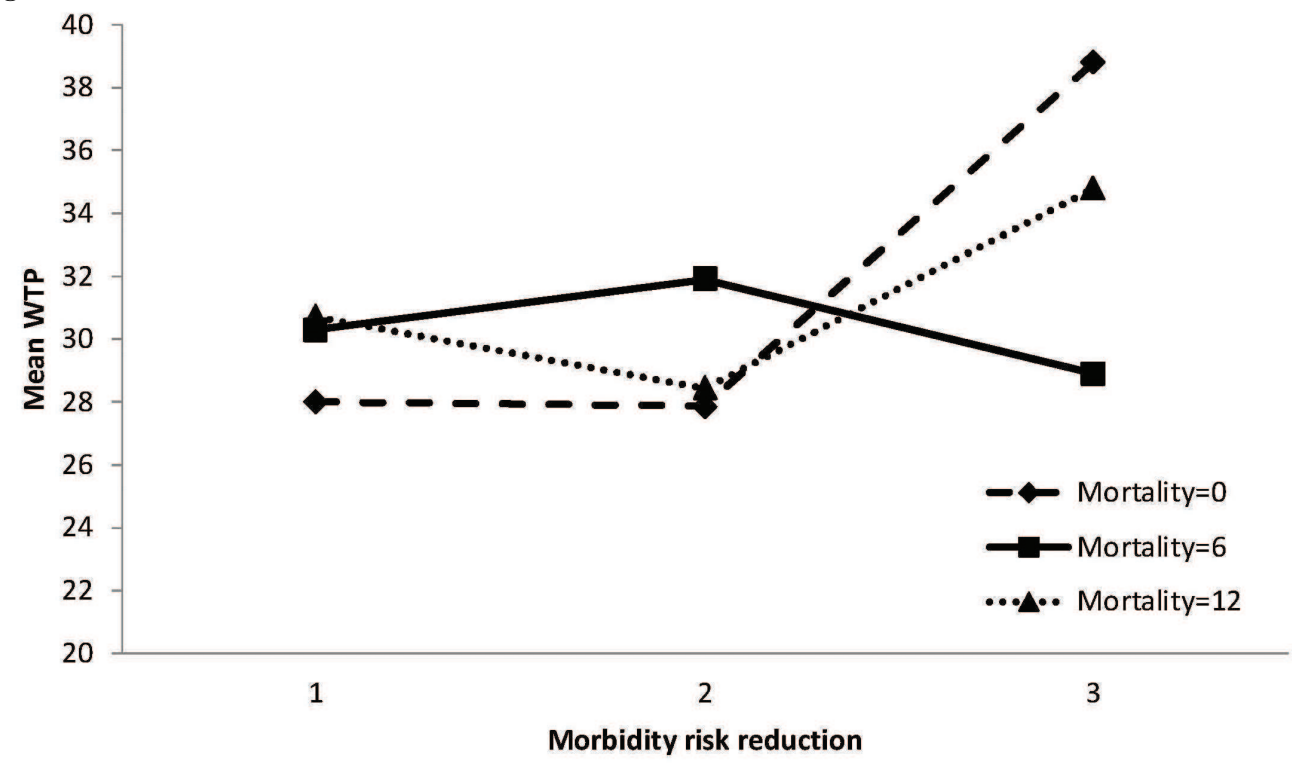


Figure 3: Value of a statistical illness (VSI): Monte Carlo simulation based on Turnbull estimator

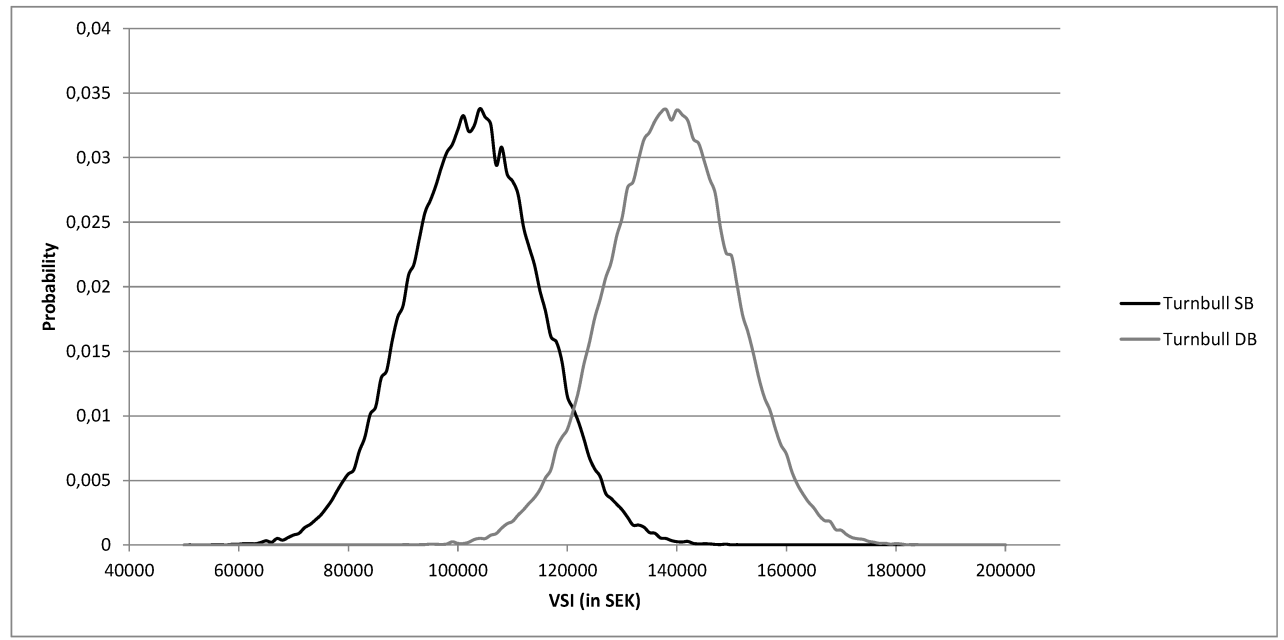

Table 1: The three different variants of salmonellosis and their respective probabilities, symptoms and duration

\begin{tabular}{|c|c|c|c|}
\hline Variant ( $\%$ of cases) & Symptoms & Duration & $\begin{array}{l}\text { Consultation of GP/ } \\
\text { hospitalization }\end{array}$ \\
\hline Mild $(75 \%)$ & $\begin{array}{l}\text { vomiting, diarrhoea, nausea } \\
\text { and cramps }\end{array}$ & $2-3$ days & no consultation \\
\hline Moderate (23\%) & $\begin{array}{l}\text { as mild, but more vomiting } \\
\text { and cramps per day }\end{array}$ & 3-7 days & $\begin{array}{l}\text { consultation of GP but } \\
\text { no hospitalization }\end{array}$ \\
\hline Severe $(2 \%)$ & $\begin{array}{l}\text { as moderate but also fever, } \\
\text { headache and muscle pains }\end{array}$ & 15 -20 days or more & $\begin{array}{l}\text { consultation of GP and } \\
\text { hospitalization }\end{array}$ \\
\hline
\end{tabular}

Table 2: Different combinations of morbidity and mortality risk reductions used in the survey

\begin{tabular}{|c|c|c|c|}
\hline $\begin{array}{l}\text { Morbidity risk } \\
\text { reductions }\end{array}$ & \multicolumn{3}{|c|}{ Mortality risk reductions } \\
\hline $\begin{array}{l}4 \rightarrow 2 \text { in } 10000 \\
(2 \text { in } 10000)\end{array}$ & $\begin{array}{r}0 \rightarrow 0 \text { in } 100 \text { million } \\
\quad(0 \text { in } 100 \text { million })\end{array}$ & $\begin{array}{r}6 \rightarrow 3 \text { in } 100 \text { million } \\
\quad(3 \text { in } 100 \text { million })\end{array}$ & $\begin{array}{r}12 \rightarrow 6 \text { in } 100 \text { million } \\
\quad(6 \text { in } 100 \text { million })\end{array}$ \\
\hline $\begin{array}{l}4 \rightarrow 1 \text { in } 10000 \\
(3 \text { in } 10000)\end{array}$ & $\begin{array}{r}0 \rightarrow 0 \text { in } 100 \text { million } \\
\quad(0 \text { in } 100 \text { million })\end{array}$ & $\begin{array}{r}6 \rightarrow 1,5 \text { in } 100 \text { million } \\
(4,5 \text { in } 100 \text { million }\end{array}$ & $\begin{array}{l}12 \rightarrow 3 \text { in } 100 \text { million } \\
\quad(9 \text { in } 100 \text { million })\end{array}$ \\
\hline $\begin{array}{l}3 \rightarrow 2 \text { in } 10000 \\
(1 \text { in } 10000)\end{array}$ & $\begin{array}{r}0 \rightarrow 0 \text { in } 100 \text { million } \\
\quad(0 \text { in } 100 \text { million }\end{array}$ & $\begin{array}{r}6 \rightarrow 4 \text { in } 100 \text { million } \\
\quad(2 \text { in } 100 \text { million })\end{array}$ & $\begin{array}{l}12 \rightarrow 8 \text { in } 100 \text { million } \\
\quad \text { ( } 4 \text { in } 100 \text { million })\end{array}$ \\
\hline $\begin{array}{l}3 \rightarrow 1 \text { in } 10000 \\
(2 \text { in } 10000)\end{array}$ & $\begin{array}{l}0 \rightarrow 0 \text { in } 100 \text { million } \\
\quad(0 \text { in } 100 \text { million })\end{array}$ & $\begin{array}{l}6 \rightarrow 2 \text { in } 100 \text { million } \\
\quad(4 \text { in } 100 \text { million })\end{array}$ & $\begin{array}{l}12 \rightarrow 4 \text { in } 100 \text { million } \\
\quad(8 \text { in } 100 \text { million })\end{array}$ \\
\hline
\end{tabular}


Table 3: Descriptive statistics of respondents

\begin{tabular}{lccc}
\hline \multicolumn{1}{c}{ Variable } & Mean & (Std. Dev. $^{\mathrm{a}}$ & Population $^{\mathrm{b}}$ \\
\hline Gender (0=Male, 1=Female) & 0.59 & $(-)$ & 0.5 \\
Age of respondent & 46.13 & $(15.65)$ & 44.7 \\
Income (SEK/month) & 26220 & $(13335)$ & 22639 \\
Highest education level & & & \\
$\quad$ Elementary school & 0.18 & $(-)$ & 0.17 \\
$\quad$ Secondary school & 0.44 & $(-)$ & 0.48 \\
$\quad$ University & 0.38 & $(-)$ & 0.35 \\
Household size & 2.76 & $(1.54)$ & 2.1 \\
Marital status & & & \\
$\quad$ Married & 0.56 & $(-)$ & 0.35 \\
$\quad$ Single & 0.19 & $(-)$ & 0.2 \\
$\quad$ Cohabitee/ other & 0.25 & $(-)$ & 0.45 \\
\hline
\end{tabular}

a: To calculate std. dev. for dummies, std.dev. $(x)=\sqrt{\bar{x}(1-\bar{x})}$.

b: Gender and Age based on population data age range 18-74, whereas eduction level based on age range 25-64.

Table 4: Risk perception, knowledge, and subjective health assessment

\begin{tabular}{lrrr}
\hline Question & male & female & all \\
\hline $\begin{array}{l}\text { Q2: If we randomly select a group of 100 Swedish citizens. how } \\
\text { many of these do you think will suffer from food contamination }\end{array}$ & 7.80 & 9.55 & 8.79 \\
during one year? $^{\text {a }}$ & & & \\
Q3: How common do you think death due to food contamination & & & \\
is compared to other causes of death in Sweden? & & & \\
- Correct ranking of all death causes $^{\text {- Correct ranking of food contamination }}$ & 0.24 & 0.24 & 0.24 \\
\hline Q19: State your own current health status (0-100) & 0.50 & 0.57 & 0.54 \\
Q19: Value different salmonellosis conditions (0-100) & 91 & 89 & 90 \\
Mild variant & 65 & 63 & 64 \\
Moderate variant & 47 & 46 & 47 \\
Severe variant & 29 & 27 & 28 \\
\hline a: Geometric means & & & \\
b: Cardio-vascular diseases, lung cancer, car accidents, AIDS/HIV and food contamination.
\end{tabular}

Table 5: Self-reported knowledge of food safety

\begin{tabular}{lrrr}
\hline Q4: Self-assessed knowledge of food safety & $\begin{array}{r}\text { limited } \\
(12 \%)\end{array}$ & $\begin{array}{r}\text { average } \\
(55 \%)\end{array}$ & $\begin{array}{r}\text { extensive } \\
(33 \%)\end{array}$ \\
\hline Q2: (See previous table) & 10.23 & 8.64 & 8.60 \\
Q3: (See previous table) & & & \\
- Correct ranking of all death causes & 0.20 & 0.23 & 0.26 \\
- Correct ranking of food contamination & 0.46 & 0.56 & 0.54 \\
Q5: How important is food safety compared to the price when & 4.73 & 5.46 & 6.07 \\
you go shopping? (scale 1-7: 1 = price most important, & & & \\
7 = safety most important) & \multirow{2}{*}{0.20} & 0.24 & 0.39 \\
Q14: Is your risk of getting infectious intestinal disease & & & \\
from chicken smaller than the average risk? & &
\end{tabular}


Table 6: Value of a Statistical Illness (VSI) and WTP per QALY based Turnbull estimator

\begin{tabular}{lcrrr}
\hline & \multicolumn{4}{c}{ Value of a statistical illness } \\
\hline \multirow{3}{*}{ Single bounded } & E(WTP) & VSI & $2.5 \%$ & $97.5 \%$ \\
\cline { 2 - 5 } Double bounded & 20.66 & 103178 & 83242 & 122873 \\
& 27.86 & 139255 & 119603 & 158908 \\
\hline & \multicolumn{4}{c}{ WTP per QALY } \\
\hline \multirow{3}{*}{ Single bounded } & E(WTP) & $\Delta$ QALY & WTP per QALY \\
\cline { 2 - 5 } & 20.66 & 0.0042 & 24.60 \\
\hline
\end{tabular}

Mean WTP for a 2 in 10000 change in morbidity risk with zero mortality risk from Table 9 in SEK 2006 price level.

a: In SEK million and estimated with Eq. (10).

Table 7: Regression results single-bounded

\begin{tabular}{|c|c|c|c|c|c|c|}
\hline Variable & \multicolumn{2}{|c|}{ Model 1} & \multicolumn{2}{|c|}{ Model 2} & \multicolumn{2}{|c|}{ Model 3} \\
\hline Baseline risk ${ }_{\text {morb }}$ & -0.846 & $(0.771)$ & -0.532 & $(0.770)$ & -0.632 & $(0.728)$ \\
\hline $\ln \left(\Delta p_{\text {morb }}\right)$ & $0.557^{* *}$ & $(0.280)$ & 0.420 & $(0.278)$ & $0.471^{*}$ & $(0.263)$ \\
\hline $\ln \left(\Delta \mathrm{QALY}_{\text {morb }}\right)$ & $0.398^{* *}$ & $(0.159)$ & $0.495^{* * *}$ & $(0.178)$ & $0.369^{* *}$ & $(0.166)$ \\
\hline $\ln \left(1+\frac{\Delta \text { QALY }_{\text {mort }}}{\Delta \text { QALY }}\right)$ & -0.049 & $(0.122)$ & 0.037 & $(0.128)$ & 0.083 & $(0.121)$ \\
\hline $\ln (\text { Income })^{a}$ & & & $0.256^{*}$ & $(0.152)$ & 0.121 & $(0.148)$ \\
\hline Female $(0=\mathrm{M}, 1=\mathrm{F})$ & & & $0.473^{* * *}$ & $(0.160)$ & $0.335^{* *}$ & $(0.154)$ \\
\hline $\ln ($ Age $)$ & & & $0.649^{* * *}$ & $(0.230)$ & 0.262 & $(0.225)$ \\
\hline University highest & & & -0.064 & $(0.166)$ & -0.046 & $(0.159)$ \\
\hline Househ & & & $0.152^{* *}$ & $(0.065)$ & $0.113^{*}$ & $(0.063)$ \\
\hline $\ln ($ Healt & & & -0.058 & $(0.530)$ & -0.104 & $(0.501)$ \\
\hline Eats chicken & & & & & $-0.243^{* *}$ & $(0.122)$ \\
\hline Concern $^{b}$ & & & & & $0.514^{* *}$ & $(0.207)$ \\
\hline Price vs. Safety ${ }^{c}$ & & & & & $0.456^{* * *}$ & $(0.069)$ \\
\hline Correct ranking $^{d}$ & & & & & -0.278 & $(0.176)$ \\
\hline Reads d & & & & & -0.061 & $(0.108)$ \\
\hline $\ln ($ Freq & & & & & 0.016 & $(0.068)$ \\
\hline Lower risk & & & & & 0.198 & $(0.180)$ \\
\hline Higher 1 & & & & & 0.200 & $(0.179)$ \\
\hline Intercept & $6.238^{* * *}$ & $(1.236)$ & 1.192 & $(3.203)$ & 1.309 & $(3.071)$ \\
\hline $\mathrm{N}$ & \multicolumn{2}{|c|}{718} & \multicolumn{2}{|c|}{718} & \multicolumn{2}{|c|}{718} \\
\hline $\mathrm{PS}_{\mathrm{S}}$ & \multicolumn{2}{|c|}{0.196} & \multicolumn{2}{|c|}{0.220} & \multicolumn{2}{|c|}{0.300} \\
\hline Cohen's $f^{2, f}$ & \multicolumn{2}{|c|}{0.023} & \multicolumn{2}{|c|}{0.031} & \multicolumn{2}{|c|}{0.039} \\
\hline
\end{tabular}

Significance levels: * $10 \%,{ }^{* *} 5 \%, * * * 1 \%$

a: Income per consumption unit (which takes into account household size and age composition)

b: Concerned about illnesses like salmonellosis when shopping

c: Coded on a scale from 1 (price much more important) to 7 (safety much more important)

d: Dummy coded as 1 if respondent ranked the probabilities of different causes of death correctly

e: Stated probability of getting food contamination annually

$\mathrm{f}$ : Cohen's $f^{2}$ is a measure of effect size. To calculate the effect, we have assumed a statistical power of 0.8 , a significance level of 0.01 , the actual sample size of 718 and number of predictors equal to the numbers used in the respective model. By convention, 0.02, 0.15 and 0.35 are considered small, medium and large effects, respectively. 